\title{
A Survey and Perspectives on Mathematical Models for Quantitative Precipitation Estimation Using Lightning
}

\author{
Carlos Manuel Minjarez-Sosa and Julio Waissman \\ Departamento de Física, Departamento de Matemáticas, Universidad de Sonora, Blvd. Luis Encinas y Rosales s/n, \\ 83000 Hermosillo, SON, Mexico \\ Correspondence should be addressed to Julio Waissman; juliowaissman@mat.uson.mx
}

Received 1 February 2017; Accepted 27 April 2017; Published 17 July 2017

Academic Editor: Harry D. Kambezidis

Copyright (C) 2017 Carlos Manuel Minjarez-Sosa and Julio Waissman. This is an open access article distributed under the Creative Commons Attribution License, which permits unrestricted use, distribution, and reproduction in any medium, provided the original work is properly cited.

\begin{abstract}
Lightning is one of the most spectacular phenomena in nature. It is produced when there is a breakdown in the resistance in the electric field between the ground and an electrically charged cloud. By simple observation, we observe that precipitation, especially the most intense, is often accompanied by lightning. Given this observation, lightning has been employed to estimate convective precipitation since 1969. In early studies, mathematical models were deduced to quantify this relationship and used to estimate precipitation. Currently, the use of several techniques to estimate precipitation is gaining momentum, and lightning is one of the novel techniques to complement the traditional techniques for Quantitative Precipitation Estimation. In this paper, the authors provide a survey of the mathematical methods employed to estimate precipitation through the use of cloud-to-ground lightning. We also offer a perspective on the future research to this end.
\end{abstract}

\section{Introduction}

The estimation of precipitation is important because of its impact on several aspects of human life [1-5]. Depending on the spatial and temporal scales, the accuracy of Quantitative Precipitation Estimation (QPE) can impact several fields such as hydrology, water resources, agriculture, natural hazards, drought, climatology, meteorology, among many others $[2,3$, $6,7]$.

Rain gauges and radars have traditionally been used to monitor and estimate precipitation [8-11]. Both instruments have their own strengths and weaknesses and these have been documented in a number of authors [6,12-18], among many others. As a result, researchers and agencies have opted to combine these two measurements in order to get more accurate QPE [6, 8-11, 19]. Multisensor precipitation estimation (MPE) consists of merging network radar data with gauge bias correction [6] plus model inputs and quality controlled data. Examples of these data are the stage IV data [20] and NMQ precipitation data [21], among others. Although the MPE represents progress in estimating QPE, the accuracy of these estimations, especially in mountainous regions, has been questioned [22].
Satellites data also has been proposed as an alternative to complement ground-based MPE. It has almost global coverage $[7,23]$, can estimate precipitation at relatively high time and space resolution, and is not affected by topography as are other observational platforms [5, 24]. Currently, in fact, there are some data products that combine groundbased and satellite precipitation $[25,26]$, such as PERSIANN [27], CMORPH [28], and TMPA-RT [29], which actually represent an improvement in monitoring precipitation [25, 26]. However, satellite data suffers of its own limitations [7]. Reference [7] evaluated parameters like bias, probability of detection, and false alarm ratio, among others. They concluded that satellite precipitation products presented poor results in cases when high precipitation events associated with complex terrain occur. Coincidentally, in many places of the world, these kinds of events occur over mountainous zones where ground base sensors do not have spatial coverage (e.g., southwest USA) [22, 30]. Furthermore, satellite data latency may be inadequate for real-time forecasting.

Considering that the problem of sensor coverage is recurrent, even with multisensor QPE products (either ground or space-based), other alternative techniques to address this problem are required. 


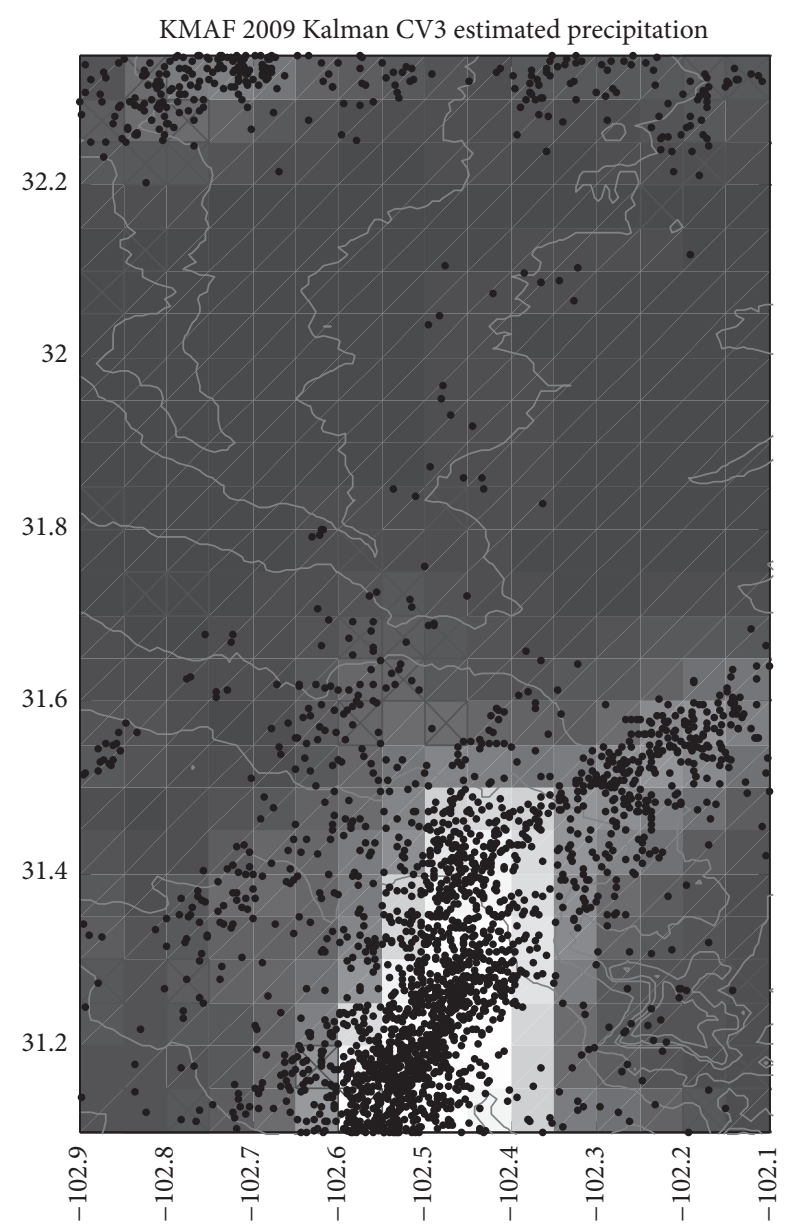

Figure 1: Convective storm in Midland, Texas, lightning-QPE correlation example, from [84].

Figure 1 shows the precipitation distribution of a thunderstorm over Mid Land, Texas. It is clear that regions with higher precipitation coincide with those with more lightning events (dots); based on this kind of observations, the relationship between cloud-to-ground lightning and convective precipitation has been proposed since the late 1950s to complement QPE estimations [31-35]. Many authors have demonstrated empirical correlation between these two variables [32-36]. In contrast with the use of radar, making use of the Lightning-Precipitation Relationship (LPR) has the advantage that, with a proper network, it can estimate precipitation in real time at high resolutions without spatial coverage problems such as mountainous regions with sparse data and weather radar blockage [22, 34]. However, this potential has not been fully explored and most of the operational QPE methods limit the use of lightning only to locate thunderstorms [37].

When studying precipitation, it is appropriate to focus on the basic types, convective and stratiform. Convective precipitation occurs predominantly in the form of localized rain showers and thunderstorms and may have greater intensity. Stratiform precipitation tends to be of larger-scale and longlasting, with lesser intensity. Disaggregated precipitation data can be used for parametrizing climate models which simulate convective and stratiform (large-scale) precipitation separately [38], as well as for analyzing climate change effects on precipitation patterns. While the recorded precipitation is often a mixture of both, convective precipitation rates are generally much higher [39]. There are a variety of algorithms to discriminate convective precipitation through subjective methods or through more sophisticated techniques (e.g., radar reflectivity [40]).

There is scientific evidence that the occurrence of lightning is linked with convective precipitation. This can be physically explained by the fact that cloud electrification processes need the presence of supercooled water, ice particles, and larger heavier graupel to coexist in a region experiencing moderately high updraft velocities $[36,41]$. Observational experiments (e.g., [42-46]) and some modeling studies (e.g., [47-49]) have established that the rate of all lightning discharges (intracloud and cloud-to-ground flashes) is strongly correlated with the rate of cloud electrification, and the latter is controlled by the convective cycles, the updraft mass flux, and the mass of ice-phase precipitation. The storm severity or the updraft intensity may not be correlated with the rates of CG flashes; however, they are correlated with the formation of precipitation and its descent to lower levels of the storm $[46,50]$.

On the other hand, lightning data have also been used in models as a proxy for deep convection to improve parameters related to cold clouds and precipitation [51-53]. Lately, researchers have investigated the utility of lightning observations for identifying convective events at several different spatial scales for which they conclude that the assimilation of lightning favorably impacts several model variables as well as initial conditions $[54,55]$.

In view of the scientific evidence, lightning based methods have been proposed as a complement or alternative for QPE [22, 32-35]. A number of studies have demonstrated the relationship between cloud-to-ground (CG) lightning and convective rainfall $[22,32-36]$. More recently, in [5], the authors demonstrated the value of combining satellite infrared and lightning information to estimate rainfall, at least for large time periods (hours to days).

In practice, many regions of the world have ground lightning detection networks [56-61]; ground global detection networks are emerging and growing, networks such as WWLLN [62] and GLD360 from Vaisala Inc. [63] are such examples. Furthermore, NASA is launching a Geostationary Lightning Mapper (GLM) which will detect total lightning (intracloud and cloud to ground) over the western hemisphere. With the aforementioned technological infrastructure in addition to the demonstrated weaknesses of the actual MPE methods previously discussed. We believe that the use of lightning based methods as a complement to convective precipitation estimation and the integration of this estimate to the current MPE may improve the rainfall estimations, warranting a further discussion of such methods.

This paper attempts to contribute to the discussion of the methods to estimate QPE by using lightning. We present a brief survey of the mathematical models used over the years and provide an overview of future research geared towards development of a system that may provide a basis to 
incorporate lightning-derived precipitation into the current multisensor precipitation products.

\section{Estimation of Lightning-Derived Precipitation}

2.1. Simple Models. Let $D$ be a spatial domain or region, divided into a gridded partition, where $A_{i, j}$ is the grid located in the $i$ th row and $j$ th column of grid partition. Let $\mathbf{s}$ be a location in $D$ and $Z_{t}(\mathbf{s})$ the rainfall in a fixed time interval in location $\mathbf{s}$ at time $t$. The QPE problem resides in estimating the spatial precipitation

$$
\widehat{Z}_{t}\left(A_{i, j}\right)=\frac{1}{\left|A_{i, j}\right|} \int_{\mathbf{s} \in A_{i, j}} Z_{t}(\mathbf{s}) d \mathbf{s},
$$

where $\left|A_{i, j}\right|$ is the area of the grid $A_{i, j}$.

In much of the previous work investigating the LPR, the mathematical model was a simple linear least squares regression $[35,36]$. In general, linearly estimated precipitation at time $t$ and $A_{i, j}$ grid can be defined as

$$
\widehat{Z}_{t}\left(A_{i, j}\right)=\left(1, f_{t}\left(L, A_{i, j}\right)\right)^{T} \Theta,
$$

where $f_{t}\left(L, A_{i, j}\right)=\left(f_{t}^{1}\left(L, A_{i, j}\right), \ldots, f_{t}^{k}\left(L, A_{i, j}\right)\right)^{T}$ is a feature vector of dimension $k$ at time $t$ from lightning observations data $L$ and $\Theta$ is a vector of estimation parameters.

The feature vector $f_{t}\left(L, A_{i, j}\right)$ can be calculated in different ways. For instance, a model can be defined by comparing the mean of convective precipitation at every time step with the corresponding lightning accumulation in the same domain. For this case, $f_{t}\left(L, A_{i, j}\right)$ is established with only one feature as $f_{t}\left(L, A_{i, j}\right)=L_{t}\left(A_{i, j}\right)$ the number of lightning occurrences in grid $A_{i, j}$ at time $t$.

In [22], the model parameters are estimated in two ways. First, in order to estimate the model parameters, a vector of mean value of precipitation and lightning is obtained as

$$
\begin{aligned}
\bar{L}_{t} & =\frac{1}{\left|D_{t}\right|} \sum_{A_{i, j} \in D} L_{t}\left(A_{i, j}\right), \\
\bar{Z}(t) & =\frac{1}{\left|D_{t}\right|} \sum_{A_{i, j} \in D} Z_{t}\left(A_{i, j}\right),
\end{aligned}
$$

where $D_{t}=\left\{A_{i, j} \mid L_{t}\left(A_{i, j}\right)>0\right\}$ is the set of grids in the domain with lightning counts different than zero at time $t$ and $\left|D_{t}\right|=\sum_{A_{i, j} \in D_{t}}\left|A_{i, j}\right|$ is the area of $D_{t}$. The parameters are obtained solving by least squares the equation

$$
\bar{Z}_{t}^{*}=\theta_{0}+\theta_{1} \bar{L}_{t}
$$

The model parameters are estimated by comparing the total seasonal convective precipitation accumulation with the total lightning strikes accumulated per grid. At this point, all the research relating LPR had correlated precipitation with discrete lightning counts. In [22] the authors proposed a method to get LPR relationships for higher time and space resolutions by using what they called Gaussian counts (GC). They noted that lightning counts and precipitation are not variables of the same nature; while precipitation is continuous quantity, lightning counts is a discrete variable. This could be a problem when using gridded data because most of the lightning events can fall in different adjacent grid than precipitation and therefore the correlation can be affected. A GC is simply defined as a convolution of every discrete count by a Gaussian distribution assuming an uncorrelated identical variance in latitude and longitude $\sigma^{2}$. The lightning Gaussian counts are obtained by

$$
\begin{aligned}
& L_{t}\left(A_{i, j}\right) \\
& \quad=\frac{1}{2 \pi \sigma^{2}} \sum_{\mathbf{s}_{l} \in D_{t}} \int_{A_{i, j}} \exp \left(-\frac{1}{2 \sigma}\left(\mathbf{s}-\mathbf{s}_{l}\right)^{T}\left(\mathbf{s}-\mathbf{s}_{l}\right)\right) d \mathbf{s} .
\end{aligned}
$$

The values of $L_{t}\left(A_{i, j}\right)$ are obtained by a simple numerical integration procedure.

2.2. Power Law Model. Based on the power law relationship that is employed for the relationship between liquid water reflectivity and precipitation rate used to estimate precipitation by radars $[32,33,64,65]$ this model has also been used to estimate lightning-derived precipitation. The model is given by

$$
\bar{L}_{t}=a\left(\bar{Z}_{t}^{*}\right)^{b}
$$

where $a$ and $b$ are the optimal parameters of the power law. This power law is equivalent to estimating a simple linear model

$$
\log \left(\bar{Z}_{t}^{*}\right)=\theta_{0}+\theta_{1} \log \left(\bar{L}_{t}\right)
$$

where $\theta_{0}=-\log (a) / b$ and $\theta_{1}=1 / b$. In [22] the authors did not find any benefit in using a power law relationship for a complex terrain domain.

2.3. Space-Time Invariant (STI) Model. Overall, previous results demonstrate that LPR is reliable when one compares relatively large regions and/or longer time periods. However, if this relationship is tested at higher resolutions (such as those of the new precipitation products), lightning events and convective precipitation may not be colocated. On the other hand, some results report a time lag between lightning and precipitation [35, 36, 66]. To address this problem, in [22], the authors proposed a model that considers spatial and time neighbors that will be described next.

Let $N_{v}\left(L_{t}\left(A_{i, j}\right)\right)=\left(L_{t}\left(A_{i-v, j-v}\right), \ldots, L_{t}\left(A_{i+v, j+v}\right)\right)$ be the Gaussian lightning counts of spatial neighboring of $A_{i, j}$ at time $t$ with $v$ vicinity. Let $f_{t}\left(L, A_{i, j}\right)$ be the temporally associated vector of lightning observations

$$
\begin{aligned}
f_{t} & \left(L, A_{i, j}\right) \\
& =\left(N_{v}\left(L_{t-\mathrm{nl}}\left(A_{i, j}\right)\right), \ldots, N_{v}\left(L_{t+\mathrm{pl}}\left(A_{i, j}\right)\right)\right),
\end{aligned}
$$

where $\mathrm{nl}$ and $\mathrm{pl}$ are the negative and positive time lags, respectively. Using the model from equation (2), the vector 


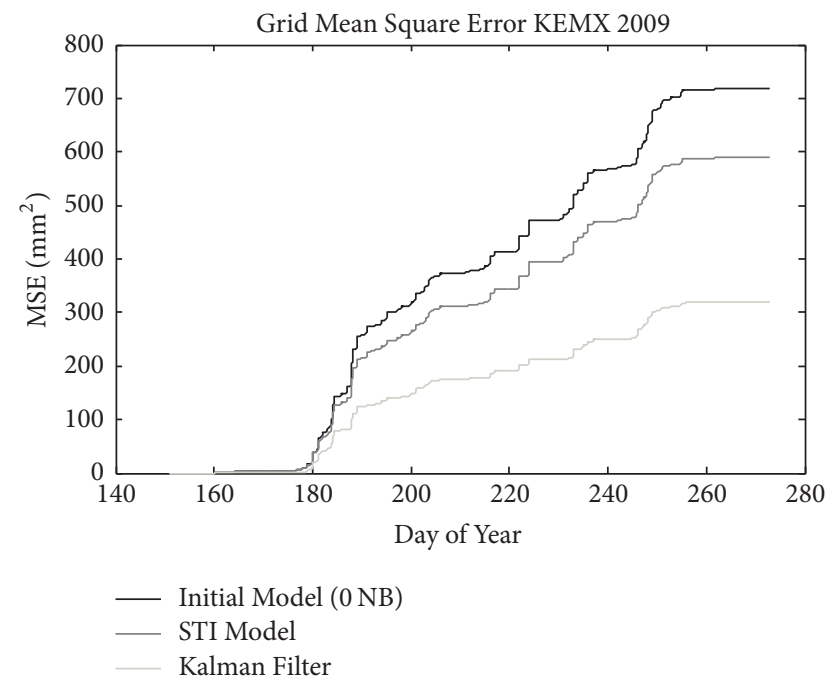

Figure 2: Cumulative total domain Mean Squared Error: simple linear model, STI model, and Kalman filter, from [84].

$\Theta$ is adjusted by least square criteria with all the convective covered grids in the relevant dataset. As will be noted further in Figure 2, the STI model improves the results with respect to the simple linear models because it allows having more parameters that consider the time lag and space relationship of the LPR.

2.4. Dynamical Linear Models. The STI model is a set of linear parameters fixed in time. Physically LPR changes from one storm to another or even within the same convective event. Therefore, a fixed time model may work better when the thunderstorms are close to the average but fails for non "typical storms." This suggests the need to develop a method to model the LPR changes in time. Let

$$
\widehat{Z}_{t}\left(A_{i, j}\right)=\left(1, f_{t}\left(L, A_{i, j}\right)\right)^{T} \Theta_{t}
$$

be model (2) with time-varying model parameters. Assume that the parameters evolve from one time step to the next one as

$$
\Theta_{t+1}=\Theta_{t}+W_{t}
$$

where $W_{t}$ is a parameter estimation error modeled as a Gaussian random variable with zero mean and a covariance matrix $Q_{t}$.

The $\Theta_{t+1}$ estimation should be realized only with the covered grids (grids with valid precipitation observations). Let $A_{\text {obs }}=\left(A_{1}, \ldots, A_{C}\right)$ be a vector of grids with observed precipitation, so

$$
Y_{t}=\left(Z_{t}\left(A_{1}\right), \ldots, Z_{t}\left(A_{C}\right)\right)+V_{t}
$$

is the observed precipitation vector at covered grids, where $V_{t}$ is the observation noise assumed to be Gaussian with zero mean and covariance $R$. The estimated precipitation of covered grids is obtained from (9) as

$$
\widehat{Y}_{t}=\Lambda(L, t) \Theta_{t}
$$

where $\Lambda(L, t)=\left(f_{t}\left(L, A_{1}\right), \ldots, f_{t}\left(L, A_{C}\right)\right)^{T}$ is the matrix whose rows are the feature vectors for each observed grid.

Equations (10) and (12) define a discrete-time linear system and thus the parameter vector $\Theta_{t}$ can be estimated by means of a Kalman filter [67] as

$$
\begin{aligned}
P_{t \mid t-1} & =P_{t-1 \mid t-1}+Q_{t}, \\
K_{t} & =P_{t \mid t-1} \Lambda(L, t)^{T}\left(\Lambda(L, t) P_{t \mid t-1} \Lambda(L, t)^{T}+R_{t}\right)^{-1}, \\
\widehat{\Theta}_{t} & =\widehat{\Theta}_{t-1}+K_{t}\left(Y_{t}-\Lambda(L, t) \Theta_{t}\right), \\
P_{t \mid t} & =\left(I-K_{t} \Lambda(L, t)\right) P_{t \mid t-1},
\end{aligned}
$$

where $P_{t \mid t}$ is the covariance estimate and $K_{t}$ is the Kalman gain matrix. At each time step $\widehat{\Theta}_{t}$ is estimated, and then the precipitation in nonobserved grids is estimated by (9).

In order to apply the Kalman filter for estimation, some conditions must be assumed, such as a zero mean Gaussian distribution of the parameters variations. Also, fixed and known covariance matrices $Q$ and $R$ are usually assumed and computed experimentally. Future research in time-varying STI models and experimental validation is required not only for lightning based QPE but in general for a large class of remote sensing models.

Figure 2 shows the benefit of the fixed STI model and the dynamic Kalman filter estimations. Comparing with the simple linear model, it is clear that the new proposed methods decrease the total mean square error down to half.

\section{Geostatistical Approach}

3.1. Geostatistical Basic Model. A random field $\mathbf{Z}$ is a set of random variables (precipitation in our case) parametrized by some set $D \subset \mathbb{R}^{n}$

$$
\mathbf{Z}=\left\{Z(\mathbf{s}): \mathbf{s} \in D \subset \mathbb{R}^{n}\right\}
$$

where $\mathbf{s}$ is a spatial coordinate. An extensive treatment of random fields' theory can be found in [68-71].

The construction of optimal predictors on a single and partial realization of a random field is based on some form of stationarity. A random field is called second-order stationary if

$$
\begin{gathered}
E[Z(\mathbf{s})]=\mu \quad \forall \mathbf{s} \in D, \\
\operatorname{Cov}\left[Z\left(\mathbf{s}_{1}\right), Z\left(\mathbf{s}_{2}\right)\right]=E\left[\left(Z\left(\mathbf{s}_{1}\right)-\mu\right)\left(Z\left(\mathbf{s}_{2}\right)-\mu\right)\right],
\end{gathered}
$$

where $E$ is the expected value operator and Cov is the covariance operator.

For processes for which the above conditions do not hold (i.e., covariance function does not exist) another hypothesis is introduced. A random field is called intrinsic stationary if

$$
\begin{array}{rlrl}
E[Z(\mathbf{s})] & =\mu & & \forall \mathbf{s} \in D \\
\text { or } E\left[Z\left(\mathbf{s}_{1}\right)-Z\left(\mathbf{s}_{2}\right)\right]=0 & \forall \mathbf{s}_{1}, \mathbf{s}_{2} \in D .
\end{array}
$$

If additionally the covariance $\operatorname{Cov}\left[Z\left(\mathbf{s}_{1}\right), Z\left(\mathbf{s}_{2}\right)\right]$ depends only on the separation between $\mathbf{s}_{1}$ and $\mathbf{s}_{2}$, then the random field is called isotropic. 
Let

$$
V\left[Z\left(\mathbf{s}_{1}\right)-Z\left(\mathbf{s}_{2}\right)\right]=2 \gamma(h),
$$

be the variance between the precipitation on two spatial coordinates and let $h=\left\|\mathbf{s}_{1}-\mathbf{s}_{2}\right\|$ be the distance between $\mathbf{s}_{1}$ and $\mathbf{s}_{2}$. The semivariogram $\gamma$ is expressed by means of expected value operator. The semivariogram as a structural function of intrinsically stationary random fields describes a broader class of phenomena, where covariance may not exist. Additionally, semivariogram does not require the mean value of a random field to be known; therefore it became the preferred function of geostatistician. In case of second-order stationary spatial processes, the covariance operator and the semivariogram are related as

$$
\gamma(h)=\operatorname{Cov}\left[Z\left(\mathbf{s}_{1}\right), Z\left(\mathbf{s}_{1}\right)\right]-\operatorname{Cov}\left[Z\left(\mathbf{s}_{1}\right), Z\left(\mathbf{s}_{2}\right)\right] .
$$

The semivariogram is a measure of dissimilarity between a pair of observations. As a function, it provides information on spatial continuity and variability of a random field. The inference on the shape is based on empirical semivariogram $g(\mathbf{h})$ and some a priori knowledge of the behavior of a phenomenon. In [72] the author presents three types of models for the fitting of the experimental semivariogram well adapted for precipitation estimation.

(i) The spherical model with range $a$ :

$$
g(h)= \begin{cases}1.5 \frac{h}{a}-0.5\left(\frac{h}{a}\right)^{3}, & \text { if } h \leq a \\ 1, & \text { otherwise. }\end{cases}
$$

(ii) The cubic model with range $a$ :

$$
g(h)= \begin{cases}7\left(\frac{h}{a}\right)^{2}-8.75\left(\frac{h}{a}\right)^{3}+3.5\left(\frac{h}{a}\right)^{5}-0.75\left(\frac{h}{a}\right)^{7}, & \text { if } h \leq a \\ 1, & \text { otherwise }\end{cases}
$$

(iii) The dampened hole effect model:

$$
g(h)=1-\exp \left(-\frac{3 h}{d}\right) \cos \left(\frac{\pi h}{d}\right),
$$

where $d$ is the distance at which $95 \%$ of the hole effect is dampened out.

The most common algorithm of geostatistical estimation is the so-called ordinary kriging which can be viewed as heterogeneously linear estimator [69]

$$
\widehat{Z}\left(\mathbf{s}_{0}\right)=\lambda\left(\mathbf{s}_{0}\right)^{T} \mathbf{Z}(\mathbf{s}),
$$

assuming $\mathbf{Z}$ is a second-order stationary random field with constant unknown mean value, $\mathbf{Z}(\mathbf{s})=\left(Z\left(\mathbf{s}_{1}\right), \ldots\right.$, $\left.Z\left(\mathbf{s}_{m}\right)\right)^{T}$ is the vector of $m$ observed data, and $\lambda\left(\mathbf{s}_{0}\right)=\left(\lambda_{1}\left(\mathbf{s}_{0}\right)\right.$, $\left.\ldots, \lambda_{m}\left(\mathbf{s}_{0}\right)\right)^{T}$ is the parameters vectors for the spatial location $\mathbf{s}_{0}$.

Ordinary kriging is a minimal variance estimator, given by $E\left[\lambda\left(\mathbf{s}_{0}\right)^{T} \mathbf{Z}(\mathbf{s})-Z\left(\mathbf{s}_{0}\right)\right]^{2}$ under the condition (15):

$$
\begin{aligned}
E\left[\widehat{Z}\left(\mathbf{s}_{0}\right)-Z\left(\mathbf{s}_{0}\right)\right] & =E\left[\boldsymbol{\lambda}\left(\mathbf{s}_{0}\right)^{T} \mathbf{Z}(\mathbf{s})-Z\left(\mathbf{s}_{0}\right)\right] \\
& =\mu\left(\lambda\left(\mathbf{s}_{0}\right)^{T} \mathbf{1}-1\right)=0 .
\end{aligned}
$$

Hence, the objective function to be minimized through Lagrange multipliers can be expressed as

$$
\begin{aligned}
J\left(\lambda\left(\mathbf{s}_{0}\right), \alpha\right)= & E\left[\boldsymbol{\lambda}\left(\mathbf{s}_{0}\right)^{T} \mathbf{Z}(\mathbf{s})-Z\left(\mathbf{s}_{0}\right)\right]^{2} \\
& -2 \alpha\left(\lambda\left(\mathbf{s}_{0}\right)^{T} \mathbf{1}-1\right) .
\end{aligned}
$$

Taking partial derivatives with respect to $\lambda_{j}\left(\mathbf{s}_{0}\right)$ and $\alpha$, and setting them to zero, provides the system of $m+1$ equations with $m+1$ unknowns:

$$
\begin{aligned}
\sum_{j=1}^{m} \lambda_{j}\left(\mathbf{s}_{0}\right) \gamma\left(\mathbf{s}_{i}-\mathbf{s}_{j}\right)-\alpha & =\gamma\left(\mathbf{s}_{i}-\mathbf{s}_{0}\right), \quad i=1, \ldots, m \\
\sum_{j=1}^{m} \lambda_{j}\left(\mathbf{s}_{0}\right) & =1 .
\end{aligned}
$$

The ordinary kriging approach is the simplest practical model for geostatistical estimation. There are several modifications of ordinary kriging; some deal with a nonconstant mean like kriging with a trend or universal kriging; some others deal with nonlinear transformations of the random field, such as indicator kriging or log-normal kriging [69, 73, 74]. In general these approaches are straight forward from the ordinary kriging.

3.2. Block Kriging. The ordinary kriging is a punctual estimator, while the QPE is a spatial estimation. Therefore, it is necessary to modify the method. Let $A$ be a defined area; then

$$
Z(A)=\frac{1}{|A|} \int_{A} Z(\mathbf{s}) d \mathbf{s}
$$

is the area average of $\mathbf{Z}$ over $A$. Intuitively, $Z(A)$ can be estimated by first estimating $Z$ (s) for a large number of locations in $A$ and then using the average of these values. That suggests a solution to the problem of how to estimate an area average by ordinary kriging

$$
\widehat{Z}(A)=\lambda(A)^{T} \mathbf{Z}(\mathbf{s}),
$$


and, again, $\lambda(A)$ is determined by imposing the same conditions of some kriging approach. If the constraint used in ordinary kriging is applied, then the equations to solve the ordinary block kriging are

$$
\begin{aligned}
\sum_{j=1}^{m} \lambda_{j}(A) \gamma\left(\mathbf{s}_{i}-\mathbf{s}_{j}\right)-\alpha & =\gamma\left(\mathbf{s}_{i}, A\right), \quad i=1, \ldots, m \\
\sum_{j=1}^{m} \lambda_{j}(A) & =1,
\end{aligned}
$$

where $\gamma\left(\mathbf{s}_{i}, A\right)$ is the point-to-block average variogram. In contrast to the average of the estimated values in $A$, this has been replaced by averaging values of the variogram. In practice, these point-to-block average variograms are obtained numerically from an empirical variogram on a regular spaced grid in $A$.

It can be shown that this is equivalent to using ordinary kriging in each grid point, thus averaging the estimated values. However, there are several important differences. First, since the distribution of the unknown values is itself unknown, it is not possible to predict the appropriate choice of the grid to obtain a given error tolerance when averaging the kriged estimates. On the contrary, it is possible to estimate an appropriate grid when numerically integrating a known function. Secondly, this approach results in many estimation errors (one for each kriged estimate) and many kriging standard deviations. In contrast, it blocks kriging results in a single kriging standard deviation for a given area and controllable numerical integration errors.

3.3. Kriging with External Drift. Kriging with external drift is a method to merge two sources of spatial information: a primary variable that is precise but only known at few locations and a secondary variable that is available in the spatial domain [75]. The primary variable is considered a random field $\mathbf{Z}$ with a nonconstant mean, but rather depends on the location. In particular it is assumed that $E[Z(\mathbf{s})]$ is a function of a secondary variable $Y(\mathbf{s})$. The simplest representation might be

$$
E\left[Z\left(\mathbf{s}_{0}\right)\right]=\sum_{i=1}^{n} a_{i} Y\left(\mathbf{s}_{0}\right)^{i}+b,
$$

where coefficients are assumed unknown. The kriging estimator form would not change from (23). For a $n=1$ the following constraints are sufficient:

$$
\begin{gathered}
\sum_{j=1}^{m} \lambda_{j}\left(\mathbf{s}_{0}\right)=1, \\
\sum_{j=1}^{m} \lambda_{j}\left(\mathbf{s}_{0}\right) Y\left(\mathbf{s}_{j}\right)=Y\left(\mathbf{s}_{0}\right),
\end{gathered}
$$

whereas for $n>1$ the additional constraints

$$
\sum_{j=1}^{m} \lambda_{j}\left(\mathbf{s}_{0}\right) Y\left(\mathbf{s}_{j}\right)^{i}=Y\left(\mathbf{s}_{0}\right)^{i}, \quad i=2, \ldots, n
$$

would be necessary. To minimize the estimation variance subject to these constraints several Lagrange multipliers would be necessary. Note that (30) might be thought of as a regression model, then the residuals are used to estimate and model the variogram function of $Z\left(\mathbf{s}_{0}\right)$.

For QPE several authors have used block kriging with external drift with elevation as the secondary variable. In the reviewed literature, there is a dearth in the research on the use of lightning data to carry out kriging with external drift. Nevertheless, there is physical and modeling evidence that justifies the assumption that the expected value of the QPE is dependent on the lightning values.

\section{Probabilistic Quantitative Precipitation Estimation}

4.1. Simulation Approach. Quantitative precipitation estimates often have significant uncertainty. Stochastic precipitation models provide an alternative framework for Quantitative Precipitation Estimation [76-78]. Most stochastic precipitation models are developed for the purposes of precipitation simulation rather than conditional precipitation estimation. The parameters of such simulation models are estimated from station data, but the temporal variability is generally not constrained to fit station observations.

In [79] a method for conditional precipitation estimation is proposed, based on a locally weighted regression, in which observed grid information are used as explanatory variables to predict spatial variability in precipitation. For each time step, regression models are used to estimate the conditional cumulative distribution function of precipitation at each grid cell and ensembles are generated by sampling to extract values from the gridded precipitation cumulative distribution function.

Based on this idea, one approach to perform probabilistic QPE based on lightning data is to compute an empirical climatological cumulative distribution function of precipitation in grids with observed precipitation and using a lightning based kriging with external drift to estimate a locally weighted regression for each grid. This model will be used to estimate a conditional cumulative distribution function of precipitation at each grid.

4.2. Conditional Random Fields. Another approach to probabilistic QPE is to model the conditional probability distribution function of each grid $\operatorname{Pr}\left(Z_{t}\left(A_{i, j}\right) \mid L_{t}\right)$ as a continuous conditional random field [80]. Let

$$
\begin{aligned}
\operatorname{Pr} & \left(Z_{t}\left(A_{i, j}\right) \mid L_{t}\right) \\
& =\frac{1}{N\left(L_{t}, \alpha\right)} \exp \left(\sum_{k=1}^{K} \alpha_{k} f_{k}\left(Z_{t}\left(A_{i, j}\right), L_{t}\right)\right),
\end{aligned}
$$

where $f_{k}(\cdot, \cdot)$ are known as feature functions, $\alpha=\left(\alpha_{1}, \ldots, \alpha_{K}\right)$ is the coefficients vector, and $N(\cdot, \cdot)$ is a normalization function

$$
N\left(L_{t}, \alpha\right)=\int_{Z} \exp \left(\sum_{k=1}^{K} \alpha_{k} f_{k}\left(Z, L_{t}\right)\right) d Z .
$$



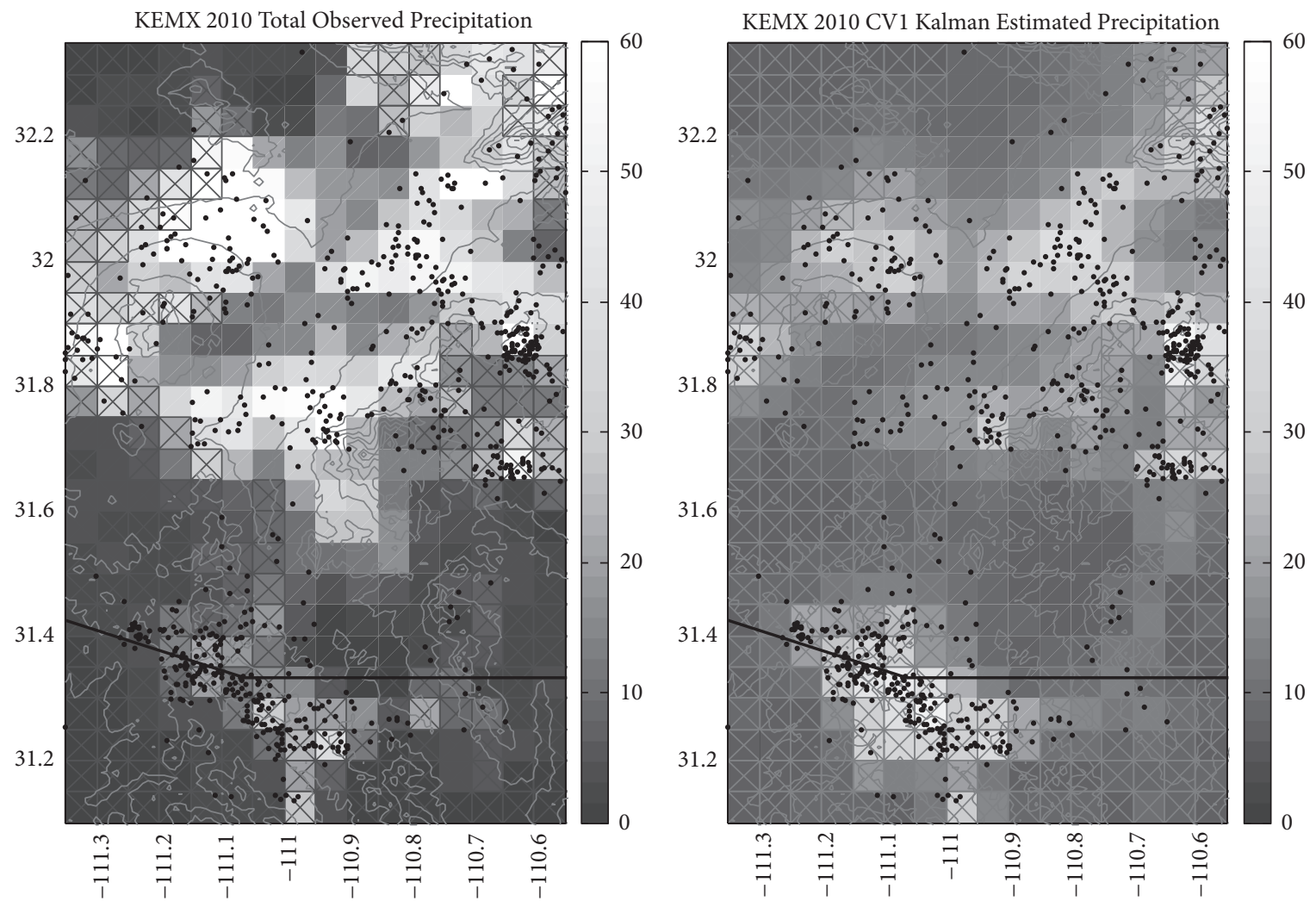

Figure 3: Precipitation map for a Mesoscale Convective System in southern Arizona. Dots are lightning strikes; grids with crosses do not have precipitation sensor coverage, from [84].

The coefficients vector is obtained by maximization of the log-likelihood criteria

$$
\begin{aligned}
J(\alpha) & =\sum_{Z_{t}\left(A_{i, j}\right) \in Z O} \log \operatorname{Pr}\left(Z_{t}\left(A_{i, j}\right) \mid L_{t}\right), \\
\alpha^{*} & =\arg \max _{\alpha} J(\alpha),
\end{aligned}
$$

where $Z O$ is the set of grids in the domain with observed precipitation. In general, to evaluate $\operatorname{Pr}\left(Z_{t}\left(A_{i, j}\right) \quad \mid L_{t}\right)$ for inference or optimization, one would need to use time consuming sampling methods such as Markov Chain Monte Carlo-based algorithms. However, in [80], it is argued that there is an efficient algorithm for optimization if the feature functions are defined as

$$
f_{k}\left(Z_{t}\left(A_{i, j}\right), L_{t}\right)=I_{k}\left(L_{t}\right)\left(Z_{t}\left(A_{i, j}\right)-\mu_{k}\left(L_{t}\right)\right)^{2}
$$

where $I_{k}(\cdot)$ is an indicator function, based on the expert knowledge of a problem. By introducing indicator functions we essentially make a partition of the whole data set of observed precipitations into smaller subsets. For each subset the learning problem is convex and a global optimal solution can be estimated by a EM approach. Estimated $\alpha_{k}$ represents our belief in $\mu_{k}\left(L_{t}\right)$ in different subsets, corresponding to different prediction conditions.

\section{Storm Tracking}

The benefit of using a dynamic model to track LPR is evident in Figure 2. However, even in this case, the spatial extension of the domain may contain more than one storm and each of these storms can be described by different models. For instance, Figure 3 shows a case in southern Arizona where it is clear that we have two LPR behaviors, one in the southern domain (non-sensor-covered domain), characterized by larger lightning events and the central north area where there were not many lightning events, but there was intense precipitation. In order to address this problem, one additional improvement to the dynamic model is to develop a method to follow in space and time LPR. Methods of clustering may be employed in order to recognize storms in the spatial domain.

In the clustering problem, we are given a training set (the lightning locations at one interval time in this case) and want to group the data into a few cohesive clusters [81]. Clustering can be achieved by various algorithms that differ significantly in their notion of what constitutes cohesive clusters. Popular notions of cohesive clusters include groups with small distances among the cluster members, dense areas of the data space, intervals, or particular statistical distributions.

Since storms change with time, it is important to capture the main transitions. In recent years, there has been an increasing interest in tracking scenarios in which a very large number of coordinated objects evolve and interact. It should 
be noted that clusters can be thought of as extended objects that produce a large number of observations. In recent work [82] merging and splitting objects are modeled using point processes. This is a fundamental issue characterizing storm behavior.

Assume that at time $t$ there are $s_{t}$ storms, or clusters at unknown locations. Assume that the storms can be adequately represented by a parametric statistical model $p\left(S_{t}\right)$ $\left.\phi_{t}\right)$. Each storm may produce more than one lightning yielding the realization set $l_{t}=\left\{\mathbf{s}_{1}^{\prime}, \ldots, \mathbf{s}_{m_{t}}^{\prime}\right\}$, where typically $m_{t} \gg s_{t}$. Let $L_{1: t}=\left\{L_{1}, \ldots, L_{t}\right\}$ be the lighting location history up to time $t$ and $l_{1: t}=\left\{l_{1}, \ldots, l_{t}\right\}$ its realization. The storm tracking problem could be defined as the estimation of the posterior distribution of the random set of unknown parameters $p\left(\phi_{t} \mid l_{1: t}\right)$ from which point estimates for $\phi_{t}$ and posterior confidence intervals can be extracted. In [83] a filtering algorithm for tracking multiple clusters of coordinated objects is presented. The algorithm is based on a MCMC mechanism. A dynamic Gaussian mixture model is utilized for representing the time-varying clustering structure.

\section{Conclusions}

In this paper, several approaches for estimating QPE from lightning measurements were reviewed. We also reviewed the existing techniques for storm tracking, since these methods can be used in conjunction with linear models, allowing a better parametrization of the models for convective events.

Linear models assume implicitly that the data used to parametrize the model is independent, normal, and homogeneous in variance. The most simple models are suitable for a first approach or when the data are expensive or limited. On the other hand, the STI models provide a powerful tool to easily express a heuristic knowledge about the spacetime relation of lightning with QPE. Dynamical STI models allow adjustment of the STI model in response to changes in LPR from one storm to another (or even in the same convective event). However, for these models to be effective it is necessary to carry out an adjustment phase of the tracking parameters, which is critical for the quality of the estimation.

Geostatistical methods generate smooth interpolated surfaces, where the estimation errors depend strongly on the assumed probability distribution, derived from the variogram model. Kriging methods are suitable when there is sufficient data to establish (and statistically verify) a variogram function. On the other hand, discriminant models (such as conditional random fields) require less assumptions about the distribution of the data and the structure of the model, so it is possible to reduce estimation errors. However, discriminative models do not offer clear representations of relations between lightning and convective precipitation. These models are suitable in large regions, with a large amount of historical data.

As mentioned at the end of Section 1, efforts to detect lightning globally with both ground-based and space-based sensors have increased in recent years. An example of this is the Vaisala GLD360 network [63], which is capable of detecting approximately $80 \%$ of events occurring all over the planet. On the other hand, NASA's next mission to put the new generation of GOES satellites into orbit will be launched in late 2017 [85]. This new generation of satellites has a lightning mapper, which implies that the entire network will be able to monitor lightning events at a global level. This implies that, as never before, electrical activity due to thunderstorms will be able to be studied and observed over the entire planet.

This infrastructure represents a great opportunity to investigate the relationship between convective precipitation and the occurrence of lightning at a global level. It Investigates the differences that may exist in LPR depending on the geographic location as well as the nature of the different convective events. The development of new algorithms and mathematical models for the estimation of convective precipitation as well as those that emerge from other investigations will be of great importance to develop systems of prediction of severe storms, to study the physical relationship between LPR for convective events of different nature, or simply to complement existing methods and techniques for estimating precipitation.

\section{Conflicts of Interest}

The authors declare that there are no conflicts of interest regarding the publication of this paper.

\section{References}

[1] J. M. Fritsch and R. E. Carbone, "Improving quantitative precipitation forecasts in the warm season: a USWRP research and development strategy," Bulletin of the American Meteorological Society, vol. 85, no. 7, pp. 955-965, 2004.

[2] E. E. Ebert, J. E. Janowiak, and C. Kidd, "Comparison of nearreal-time precipitation estimates from satellite observations and numerical models," Bulletin of the American Meteorological Society, vol. 88, no. 1, pp. 47-64, 2007.

[3] S. V. Vasiloff, D.-J. Seo, K. W. Howard et al., "Improving QPE and very short term QPF: an initiative for a community-wide integrated approach," Bulletin of the American Meteorological Society, vol. 88, no. 12, pp. 1899-1911, 2007.

[4] M. Kohn, E. Galanti, C. Price, K. Lagouvardos, and V. Kotroni, "Nowcasting thunderstorms in the Mediterranean region using lightning data," Atmospheric Research, vol. 100, no. 4, pp. 489502, 2011.

[5] W. Xu, R. F. Adler, and N.-Y. Wang, "Improving geostationary satellite rainfall estimates using lightning observations: Underlying lightning-rainfall-cloud relationships," Journal of Applied Meteorology and Climatology, vol. 52, no. 1, pp. 213-229, 2013.

[6] E. Habib, B. F. Larson, and J. Graschel, "Validation of NEXRAD multisensor precipitation estimates using an experimental dense rain gauge network in south Louisiana," Journal of Hydrology, vol. 373, no. 3-4, pp. 463-478, 2009.

[7] A. Mehran and A. Aghakouchak, "Capabilities of satellite precipitation datasets to estimate heavy precipitation rates at different temporal accumulations," Hydrological Processes, vol. 28, no. 4, pp. 2262-2270, 2014. 
[8] K. M. Stellman, H. E. Fuelberg, R. Garza, and M. Mullusky, "An examination of radar and rain gauge-derive mean areal precipitation over Georgia watersheds," Weather and Forecasting, vol. 16, no. 1, pp. 133-144, 2001.

[9] Pingping Xie and P. A. Arkin, "An intercomparison of gauge observations and satellite estimates of monthly precipitation," Journal of Applied Meteorology, vol. 34, no. 5, pp. 1143-1160, 1995.

[10] A. L. Kursinski and X. Zeng, "Areal estimation of intensity and frequency of summertime precipitation over a midlatitude region," Geophysical Research Letters, vol. 33, no. 22, Article ID L22401, 2006.

[11] D. Kitzmiller, D. Miller, R. Fulton, and F. Ding, "Radar and multisensor precipitation estimation techniques in national weather service hydrologic operations," Journal of Hydrologic Engineering, vol. 18, no. 2, pp. 133-142, 2013.

[12] E. Habib and W. F. Krajewski, "Uncertainty analysis of the TRMM ground-validation radar-rainfall products: application to the TEFLUN-B field campaign," Journal of Applied Meteorology, vol. 41, no. 5, pp. 558-572, 2002.

[13] E. Morin and M. Gabella, "Radar-based quantitative precipitation estimation over Mediterranean and dry climate regimes," Journal of Geophysical Research Atmospheres, vol. 112, no. 20, Article ID D20108, 2007.

[14] G. Villarini, P. V. Mandapaka, W. F. Krajewski, and R. J. Moore, "Rainfall and sampling uncertainties: a rain gauge perspective," Journal of Geophysical Research Atmospheres, vol. 113, no. 11, Article ID D11102, 2008.

[15] W. L. Crosson, C. E. Duchon, R. Raghavan, and S. J. Goodman, "Matching method applied to composite radar data in Central Florida," Journal of Applied Meteorology, vol. 35, no. 8, pp. 12031219, 1996.

[16] R. A. Fulton, "Sensitivity of WSR-88D rainfall estimates to the rain-rate threshold and rain gauge adjustment: A flash flood case study," Weather and Forecasting, vol. 14, no. 5, pp. 604-624, 1999.

[17] W. F. Krajewski and J. A. Smith, "Radar hydrology: rainfall estimation," Advances in Water Resources, vol. 25, no. 8-12, pp. 1387-1394, 2002.

[18] E. Morin, R. A. Maddox, D. C. Goodrich, and S. Sorooshian, "Radar Z-R relationship for summer monsoon storms in Arizona," Weather and Forecasting, vol. 20, no. 4, pp. 672-679, 2005.

[19] B. R. Nelson, D. J. Seo, and D. Kim, "Multi-sensor precipitation analysis," Journal of Hydrometeorology, vol. 11, pp. 666-682, 2010.

[20] Y. Lin and K. E. Mitchell, "Ncep stage ii/iv hourly precipitation analyses: development and applications," in Proceedings of the 19th Conf. Hydrology, American Meteorological Society, San Diego, CA, USA, 2005.

[21] C. Langston, J. Zhang, and K. Howard, "Four-dimensional dynamic radar mosaic," Journal of Atmospheric and Oceanic Technology, vol. 24, no. 5, pp. 776-790, 2007.

[22] C. M. Minjarez-Sosa, C. L. Castro, K. L. Cummins, E. P. Krider, and J. Waissmann, "Toward development of improved QPE in complex terrain using cloud-to-ground lightning data: A case study for the 2005 Monsoon in Southern Arizona," Journal of Hydrometeorology, vol. 13, no. 6, pp. 1855-1873, 2012.

[23] A. Aghakouchak, A. Behrangi, S. Sorooshian, K. Hsu, and E. Amitai, "Evaluation of satellite-retrieved extreme precipitation rates across the central United States," Journal of Geophysical Research: Atmospheres, vol. 116, no. 2, Article ID D02115, 2011.
[24] E. N. Anagnostou, "Overview of overland satellite rainfall estimation for hydro-meteorological applications," Surveys in Geophysics, vol. 25, no. 5-6, pp. 511-537, 2004.

[25] S. Sorooshian, K.-L. Hsu, X. Gao, H. V. Gupta, B. Imam, and D. Braithwaite, "Evaluation of PERSIANN system satellitebased estimates of tropical rainfall," Bulletin of the American Meteorological Society, vol. 81, no. 9, pp. 2035-2046, 2000.

[26] S. Sorooshian, A. Aghakouchak, P. Arkin et al., "Advanced concepts on remote sensing of precipitation at multiple scales," Bulletin of the American Meteorological Society, vol. 92, no. 10, pp. 1353-1357, 2011.

[27] K. L. Hsu, X. Gao, S. Sorooshian, and H. V. Gupta, "Precipitation estimation from remotely sensed information using artificial neural networks," Journal of Applied Meteorology, vol. 36, no. 9, pp. 1176-1190, 1997.

[28] R. J. Joyce, J. E. Janowiak, P. A. Arkin, and P. Xie, "CMORPH: a method that produces global precipitation estimates from passive microwave and infrared data at high spatial and temporal resolution," Journal of Hydrometeorology, vol. 5, no. 3, pp. 487503, 2004.

[29] G. J. Huffman, R. F. Adler, D. T. Bolvin et al., "The TRMM Multisatellite Precipitation Analysis (TMPA): quasi-global, multiyear, combined-sensor precipitation estimates at fine scales," Journal of Hydrometeorology, vol. 8, no. 1, pp. 38-55, 2007.

[30] R. A. Maddox, J. Zhang, J. J. Gourley, and K. W. Howard, "Weather radar coverage over the contiguous United States," Weather and Forecasting, vol. 17, no. 4, pp. 927-934, 2002.

[31] W. Parczewski, "Intensity of precipitation and frequancy of electric discharges in thunderstorms," Idojurus, vol. 62, pp. 189193, 1958.

[32] L. Battan, "Some factors governing precipitation and lightning from convective clouds," Journal of Atmospheric Sciences, pp. 79-85, 1965.

[33] M. V. Piepgrass and E. P. Krider, "Lightning and surface rainfall during Florida thunderstorms ( Kennedy Space Centre, Florida).," Journal of Geophysical Research, vol. 87, no. 13, pp. 11193-11201, 1982.

[34] A. Tapia, J. A. Smith, and M. Dixon, "Estimation of convective rainfall from lightning observations," Journal of Applied Meteorology, vol. 37, no. 11, pp. 1497-1509, 1999.

[35] B. Gungle and E. P. Krider, "Cloud-to-ground lightning and surface rainfall in warm-season Florida thunderstorms," Journal of Geophysical Research Atmospheres, vol. 111, no. 19, Article ID D19203, 2006.

[36] W. A. Petersen and S. A. Rutledge, "On the relationship between cloud-to-ground lightning and convective rainfall," Geophysical Research, vol. 103, pp. 14025-14040, 1998.

[37] C. Price, Y. Yair, A. Mugnai et al., "The FLASH Project: Using lightning data to better understand and predict flash floods," Environmental Science and Policy, vol. 14, no. 7, pp. 898-911, 2011.

[38] A. Dai, "Precipitation characteristics in eighteen coupled climate models," Journal of Climate, vol. 19, no. 18, pp. 4605-4630, 2006.

[39] C. A. Leary and R. A. Houze Jr., "Melting and evaporation of hydrometeors in precipitation from the anvil clouds of deep tropical convection.", Journal of the Atmospheric Sciences, vol. 36, no. 4, pp. 669-679, 1979.

[40] S. Lang, W.-K. Tao, J. Simpson, and B. Ferrier, "Modeling of convective-stratiform precipitation processes: Sensitivity to partitioning methods," Journal of Applied Meteorology, vol. 42, no. 4, pp. 505-527, 2003. 
[41] T. Takahashi, "Near absence of lightning in torrential rainfall producing Micronesian thunderstorms," Geophysical Research Letters, vol. 17, no. 13, pp. 2381-2384, 1990.

[42] R. Lhermitte, "Doppler Radar and Radio Observations of Thunderstorms," IEEE Transactions on Geoscience Electronics, vol. 17, no. 4, pp. 162-171, 1979.

[43] D. R. Macgorman, D. W. Burgess, V. Mazur, W. D. Rust, W. L. Taylor, and B. C. Johnson, "Lightning rates relative to tornadic storm evolution on 22 May 1981," Journal of the Atmospheric Sciences, vol. 46, no. 2, pp. 221-250, 1989.

[44] K. C. Wiens, S. A. Rutledge, and S. A. Tessendorf, “The 29 June 2000 supercell observed during STEPS. Part II: Lightning and charge structure," Journal of the Atmospheric Sciences, vol. 62, no. 12, pp. 4151-4177, 2005.

[45] J. Latham, W. A. Petersen, W. Deierling, and H. J. Christian, "Field identification of a unique globally dominant mechanism of thunderstorm electrification," Quarterly Journal of the Royal Meteorological Society, vol. 133, no. 627, pp. 1453-1457, 2007.

[46] D. R. MacGorman, W. David Rust, T. J. Schuur et al., "TELEX The Thunderstorm Electrification and Lightning Experiment," Bulletin of the American Meteorological Society, vol. 89, no. 7, pp. 997-1013, 2008.

[47] M. B. Baker, H. J. Christian, and J. Latham, "A computational study of the relationships linking lightning frequency and other thundercloud parameters," Quarterly Journal of the Royal Meteorological Society, vol. 121, no. 527, pp. 1525-1548, 1995.

[48] J. Latham, A. M. Blyth, H. J. Christian Jr., W. Deierling, and A. M. Gadian, "Determination of precipitation rates and yields from lightning measurements," Journal of Hydrology, vol. 288, no. 1-2, pp. 13-19, 2004.

[49] E. R. Mansell, D. R. MacGorman, C. L. Ziegler, and J. M. Straka, "Charge structure and lightning sensitivity in a simulated multicell thunderstorm," Journal of Geophysical Research D: Atmospheres, vol. 110, no. 12, pp. 1-24, 2005.

[50] R. M. Reap and D. R. Macgorman, "Cloud-to-ground lightning: climatological characteristics and relationships to model fields, radar observations, and severe local storms," Monthly Weather Review, vol. 117, no. 3, pp. 518-535, 1989.

[51] G. D. Alexander, J. A. Weinman, V. M. Karyampudi, W. S. Olson, and A. C. L. Lee, "The effect of assimilating rain rates derived from satellites and lightning on forecasts of the 1993 superstorm," Monthly Weather Review, vol. 127, no. 7, pp. 14331457, 1999.

[52] A. T. Pessi and S. Businger, "The impact of lightning data assimilation on a winter storm simulation over the North Pacific Ocean," Monthly Weather Review, vol. 137, no. 10, pp. 3177-3195, 2009.

[53] A. O. Fierro, E. R. Mansell, C. L. Ziegler, and D. R. Macgorman, "Application of a lightning data assimilation technique in the WRF-ARW model at cloud-resolving scales for the tornado outbreak of 24 may 2011," Monthly Weather Review, vol. 140, no. 8, pp. 2609-2627, 2012.

[54] K. Apodaca, M. Zupanski, M. Demaria, J. A. Knaff, and L. D. Grasso, "Development of a hybrid variational-ensemble data assimilation technique for observed lightning tested in a mesoscale model," Nonlinear Processes in Geophysics, vol. 21, no. 5, pp. 1027-1041, 2014.

[55] A. O. Fierro, J. Gao, C. L. Ziegler, E. R. Mansell, D. R. Macgorman, and S. R. Dembek, "Evaluation of a cloud-scale lightning data assimilation technique and a 3DVAR method for the analysis and short-term forecast of the 29 june 2012 derecho event," Monthly Weather Review, vol. 142, no. 1, pp. 183-202, 2014.

[56] I. R. C. A. Pinto and J. Pinto, "Cloud-to-ground lightning distribution in Brazil," Journal of Atmospheric and Solar-Terrestrial Physics, vol. 65, no. 6, pp. 733-737, 2003.

[57] H. Höller, H.-D. Betz, K. Schmidt et al., "Lightning characteristics observed by a VLF/LF lightning detection network (LINET) in Brazil, Australia, Africa and Germany," Atmospheric Chemistry and Physics, vol. 9, no. 20, pp. 7795-7824, 2009.

[58] H. D. Betz, K. Schmidt, P. Laroche et al., "LINET-An international lightning detection network in Europe," Atmospheric Research, vol. 91, no. 2-4, pp. 564-573, 2009.

[59] K. L. Cummins and M. J. Murphy, "An overview of lightning locating systems: History, techniques, and data uses, with an in-depth look at the U.S. NLDN," IEEE Transactions on Electromagnetic Compatibility, vol. 51, no. 3, pp. 499-518, 2009.

[60] A. A. Jacques, Comparison of the United States Precision Lightning Network (TM)(USPLN (TM)) and the Cloud-to-Ground Lightning Surveillance System (CGLSS), Plymouth State University, 2011.

[61] S. M. Chen, Y. Du, L. M. Fan, H. M. He, and D. Z. Zhong, "A lightning location system in China: Its performances and applications," IEEE Transactions on Electromagnetic Compatibility, vol. 44, no. 4, pp. 555-560, 2002.

[62] C. J. Rodger, S. Werner, J. B. Brundell et al., "Detection efficiency of the VLF World-Wide Lightning Location Network (WWLLN): Initial case study," Annales Geophysicae, vol. 24, no. 12, pp. 3197-3214, 2006.

[63] S. Mallick, V. A. Rakov, T. Ngin et al., "Evaluation of the GLD360 performance characteristics using rocket-and-wire triggered lightning data," Geophysical Research Letters, vol. 41, no. 10, pp. 3636-3642, 2014.

[64] J. R. Saylor, C. W. Ulbrich, J. W. Ballentine, and J. L. Lapp, "The correlation between lightning and DSD parameters," IEEE Transactions on Geoscience and Remote Sensing, vol. 43, no. 8, pp. 1806-1815, 2005.

[65] G. D. Kinzer, "CLOUD-TO-GROUND LIGHTNING VERSUS RADAR REFLECTIVITY IN OKLAHOMA THUNDERSTORMS.," Journal of the Atmospheric Sciences, vol. 31, no. 3, pp. 787-799, 1974.

[66] S. Soula and S. Chauzy, "Some aspects of the correlation between lightning and rain activities in thunderstorms," Atmospheric Research, vol. 56, no. 1-4, pp. 355-373, 2000.

[67] T. Kailath, A. H. Sayed, and B. Hassibi, Linear Estimation, Prentice-Hall, 2000.

[68] R. J. Adler, The geometry of Random Fields, John Wiley and Sons, New York, NY, USA, 1981.

[69] G. Christakos, Random Fields Models in Earth Sciences, Dover Publications Inc., New York, NY, USA, 1992.

[70] L. M. Stein, Interpolation of Spatial Data - Some Theory for Kriging, Springer, 1999.

[71] T. Krarup, A contribution to the mathematical foundations of physical geodesy [Ph.D. thesis], Geodaetisk Institut, Kobenhavn, Denmark, 1969.

[72] P. Goovaerts, "Geostatistical approaches for incorporating elevation into the spatial interpolation of rainfall," Journal of Hydrology, vol. 228, no. 1-2, pp. 113-129, 2000.

[73] J. P. Chiles and P. Delfiner, Geostatistics, Modeling Spatial uncertainty, John Wiley and Sons, New York, NY, USA, 1999.

[74] E. H. Isaaks and R. M. Srivastava, An Introduction to Applied Geostatistics, Oxford University Press, New York, NY, USA, 1989. 
[75] G. Raspa, M. Tucci, and R. Bruno, "Reconstruction of rainfall fields by combinig ground raingauges data with radar maps using external drift methods," in Geostatistics Wollongong 96, E. Y. Baafi and N. A. Schofield, Eds., pp. 941-950, Kluwer Academic, Dordrecht, Netherlands, 1997.

[76] R. L. Bras and I. Rodriguez-Iturbe, Random Functions and Hydrology, Dover Publications Inc., New York, NY, USA, 1985.

[77] H. S. Wheater, V. S. Isham, D. R. Cox et al., "Spatial-temporal rainfall fields: Modelling and statistical aspects," Hydrology and Earth System Sciences, vol. 4, no. 4, pp. 581-601, 2000.

[78] L. Ferraris, S. Gabellani, N. Rebora, and A. Provenzale, "A comparison of stochastic models for spatial rainfall downscaling," Water Resources Research, vol. 39, article 1389, no. 12, 2003.

[79] M. P. Clark and A. G. Slater, "Probabilistic quantitative precipitation estimation in complex terrrain," Journal of Hydrometeorology, vol. 7, no. 1, pp. 3-22, 2006.

[80] V. Radosavljevic, S. Vucetic, and Z. Obradovic, "Continuous conditional random fields for regression in remote sensing," in Proceedings of the 2010 conference on ECAI 2010: 19th European Conference on Artificial Intelligence, pp. 809-814, IOS Press, Amsterdam, Netherlands, 2010.

[81] S. Theodoridis and K. Koutroumbas, Pattern Recognition, Academic Press, Burlingtown, MA, USA, 4rd edition, 2008.

[82] C. B. Storlie, T. C. M. Lee, J. Hannig, and D. Nychka, "Tracking of multiple merging and splitting targets: a statistical perspective," Statistica Sinca, vol. 19, no. 1, pp. 1-52, 2009.

[83] A. Carmi, F. Septier, and S. J. Godsill, "The Gaussian mixture MCMC particle algorithm for dynamic cluster tracking," Automatica. A Journal of IFAC, the International Federation of Automatic Control, vol. 48, no. 10, pp. 2454-2467, 2012.

[84] C. M. Minjarez-Sosa, Improved quantitative precipitation estimation over complex terrain using cloud-to-ground lightning data [Ph.D. thesis], University of Arizona, 2013.

[85] S. J. Goodman, R. J. Blakeslee, W. J. Koshak et al., "The GOES-R Geostationary Lightning Mapper (GLM)," Atmospheric Research, vol. 125-126, pp. 34-49, 2013. 

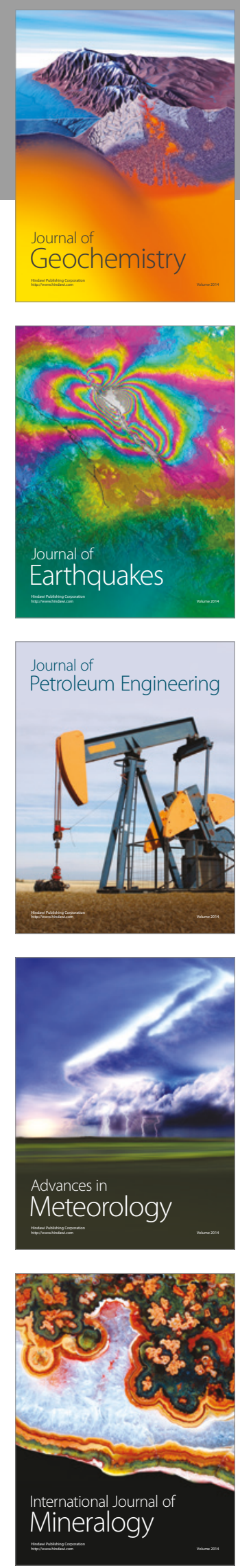
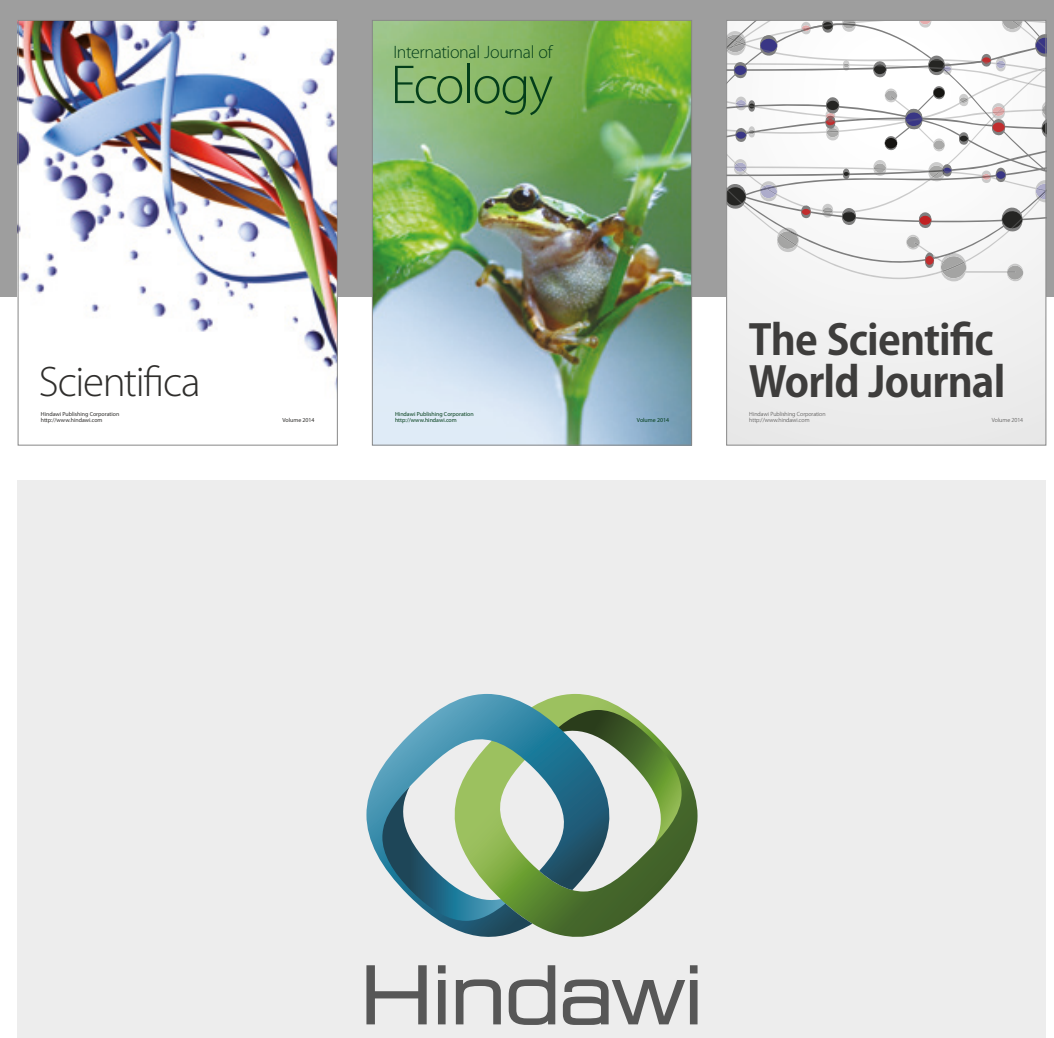

Submit your manuscripts at

https://www.hindawi.com
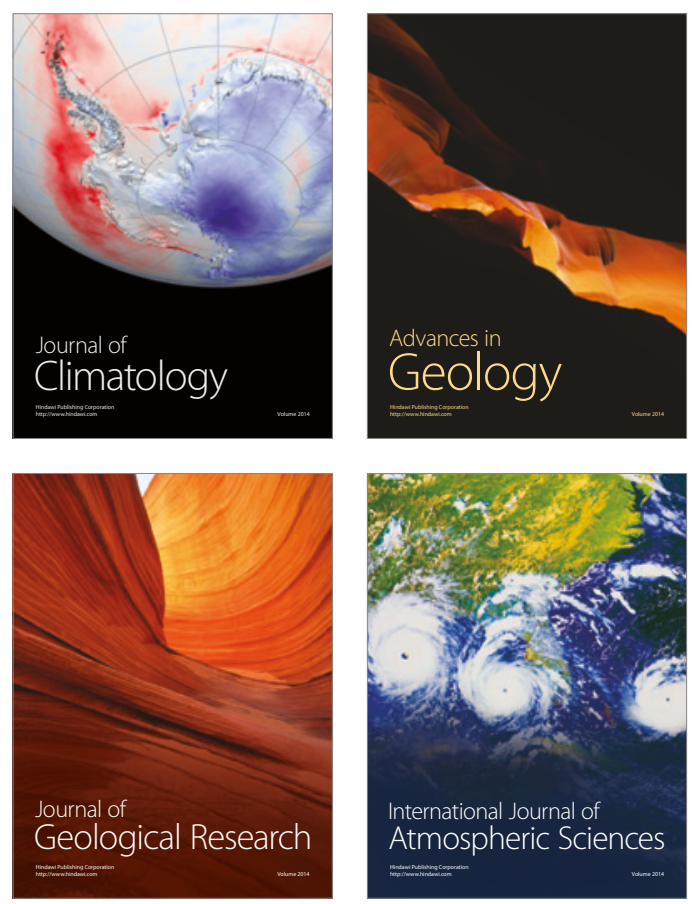

The Scientific

World Journal
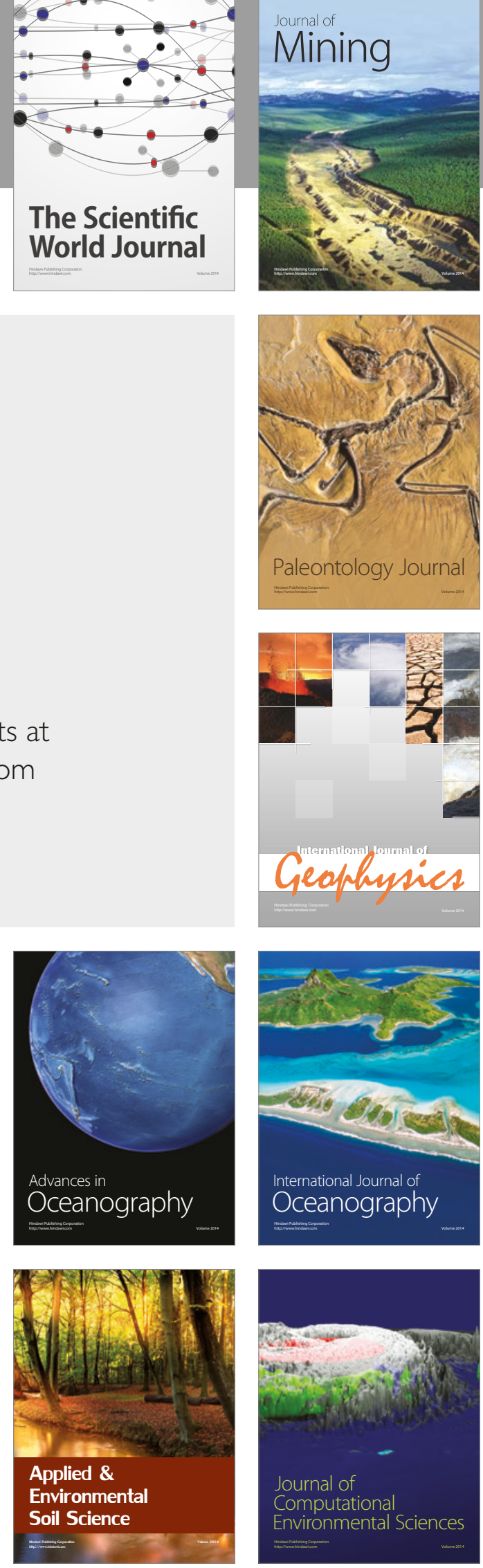